\title{
26
}

\section{Stormwater Management and Significant Channel Flows below the Two-year Return}

\section{Paul V. Villard and Ryan Ness}

Historically, hydrology and hydraulic targets and considerations associated with urban stormwater management have focused on flows equal to, or larger than, the two-year return. More recently, targets linked to concepts of effective and bankfull discharge have been defined to limit geomorphic impacts to receiving watercourses. These are generally tied to flows equal to, or of somewhat higher frequency than, the two-year return. Unfortunately, in many cases flows that have a significant impact on aquatic habitat, stream geomorphology and water quality are well below the two-year return event. A series of simple conceptual models are outlined to examine these flows. These flows are also examined in the context of the watersheds of the Greater Toronto Area, by combining simple conceptual models of these flows with geomorphic data from the Toronto and Region Conservation Authority's Regional Monitoring Network.

\subsection{Introduction}

From a hydrologic and hydraulic perspective, stormwater management tries to maintain flows to receiving watercourses below defined targets. In many

Villard, P.V. and R. Ness. 2007. "Stormwater Management and Significant Channel Flows below the Two-year Return." Journal of Water Management Modeling R227-26. doi: 10.14796/JWMM.R227-26.

(C) CHI 2007 www.chijournal.org ISSN: 2292-6062 (Formerly in Contemporary Modeling of Urban Water Systems. ISBN: 0-9736716-3-7) 
cases these targets are based on pre-development flow conditions. Historically, hydrology and hydraulic considerations associated with watershed management have focused on flows larger than the 2-y return. This is a combined consequence of the dramatic changes observed during large flow events, and the importance of flood planning in watershed management. Unfortunately, many of the flows that are significant with respect to aquatic and terrestrial habitat, stream geomorphology and water quality tend to be smaller than the 2-y event.

Baseflow and bankfull flow channel conditions, for example, have importance with respect to aquatic habitat and stream geomorphology. Bankfull flow is the rising stage when water just begins to overflow its banks and accesses the flood plain (Leopold et al, 1964). It generally has a return of 1.5-y, although it can and does vary. The significance of bankfull flows lies in the notion that it represents the long-term channel-forming discharge and is therefore an important flow in stream geomorphology. Baseflow is generally the low flow condition where flow contributions are from through flow or groundwater. It is also a term that is more generically, although incorrectly, used to describe any low flow conditions. During baseflow, or lower flow conditions, aquatic species are most vulnerable as habitat area is minimized and usually segmented. Segmentation occurs due to reduced water depth in riffles, and in some cases, isolation of pools as water moves from pool to pool as interstitial flow through individual riffles.

In examining the sensitivity of aquatic habitat to low flow or base flow conditions, one other concept - residual depth - is examined. Residual depth is the difference between the maximum (pool) depth and minimum (riffle) depth (Figure 26.1, Lisle, 1987). It represents the pool (water) depth if there was very limited flow in the channel. At these flows the riffles can become barriers to fish passage, isolating habitat. Given the varying hydraulic requirements of different fish species, determining potential loss of fish passage requires knowledge of the local fish community.

Other significant flows that usually occur more frequently than the 2-y return period flow, particularly in the southern Ontario context, are flushing flows and mobilizing flow. Flushing flows are defined as those flows that entrain fine sediments, cleaning out the fines, but not necessarily mobilizing the coarser sediments (Hey, 1975). These periodic flows are important for riffle and spawning bed maintenance (Figure 26.1). Mobilizing flows are defined as those flows that mobilize a substantial portion of the available bed material (Hey, 1975). These flows are significant in maintaining channel form (physical shape) over the long term. 


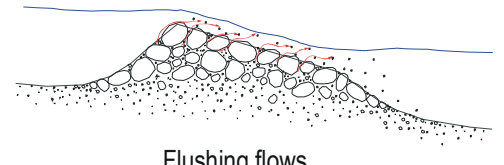

Flushing flows

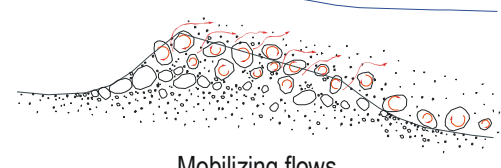

Mobilizing flows

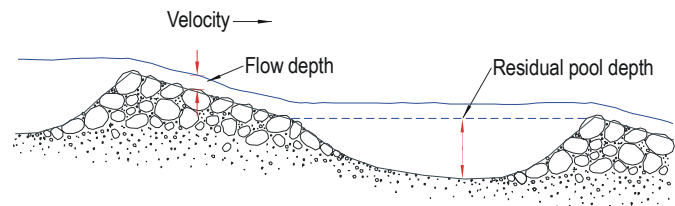

Aquatic habitat related flows

Figure 26.1 Visual representation of flushing, mobilizing and residual depth concepts.

In this chapter, these concepts, which to date have seen limited application in stormwater management, are examined in the context of southern Ontario and more specifically the Greater Toronto Area. A case study using Toronto and Region Conservation Authority (TRCA) Regional Monitoring Network data is presented to illustrate and examine potential sensitivity of creeks within the Greater Toronto Area to flows that occur below the 2-y return period.

\subsection{TRCA Regional Watershed Monitoring Network}

The Regional Watershed Monitoring Network is an ongoing program originally conceived by TRCA to develop a comprehensive, integrated and coordinated approach to environmental monitoring in the Toronto region. The program involves long-term monitoring of aquatic habitat and species, fluvial geomorphology, terrestrial habitat and fauna, and water quality. The program is intended to fulfill the watershed monitoring and reporting needs of the Toronto Remedial Action Plan (RAP) the TRCA and those of the individual watershed and waterfront councils and alliances.

With regard to geomorphic monitoring, a brief description of the relevant data collected at each monitoring site in the network is pertinent. Upon 
establishment of each site, ten cross-sections were measured over two complete meanders. Measures of the local energy gradients (i.e. current water, bankfull, riffle, and inter-pool) were collected through a level survey. At each site, bankfull cross-sectional dimensions were quantified for the reach, using standard protocols and field indicators. Sediment size distributions were developed for the bed substrate based on a modified Wolman (1954) pebble count. In addition, bank characteristics (e.g. vegetation cover, bank height and sediment composition) were collected. Long-term monitoring at geomorphic sites consists of repeat measurements at one-control cross-section and repeated pebble counts for each site, taken every three years.

In total, data from thirteen watercourses within the TRCA jurisdiction were available for this case study. The watercourses included Carruthers Creek, Centreville Creek, Cold Creek, Don River, Duffins Creek, Etobicoke Creek, Highland Creek, Humber River, Mimico Creek, Petticoat Creek, and Rouge River. Among these watercourses, data from a total of 179 monitoring site were assessed.

The geology, land cover, and physiography vary greatly between and within these watersheds. Within these watersheds, parent material, whether bedrock or till, plays a significant part in channel form and processes. Therefore, the influence of parent material on residual pool depth was examined. To assess geological control of residual depth, the data were grouped into three classes: alluvium channels (loose sediments), and semialluvial channels dominated by either exposures of till or shale. As bed material is a major control on channel geometry, these categories are used in the following examination. The data were also presented in the context of the channels bankfull conditions, whether as a function of bankfull geometry or bankfull shear stress. This indirectly addresses the other major control on channel geometry, that being the amount of flow.

\subsection{Baseflow Conditions and Residual Pool Depth}

Figure 26.2 is a plot of residual depth, i.e. the difference between maximum (pool) depth and the minimum (riffle) depth from the cross-sections at each site, as a function of bankfull width with creeks divided into three categories: alluvium channels (loose sediments), and semi-alluvial channels dominated by either exposures of till or shale. 
Figure 26.2 suggests that there is a maximum residual pool depth that can develop in till-dominated channels within the limits of this data set (dashed line is a fit-by-eye of this maximum). This does not appear to be the case with shale-dominated channels, possibly as a result of the susceptibility of shale to weathering and tendency to fracture. The two outliers circled in Figure 26.2 are from the lower Humber River; these have very limited gradient and are impacted by backwater effects.

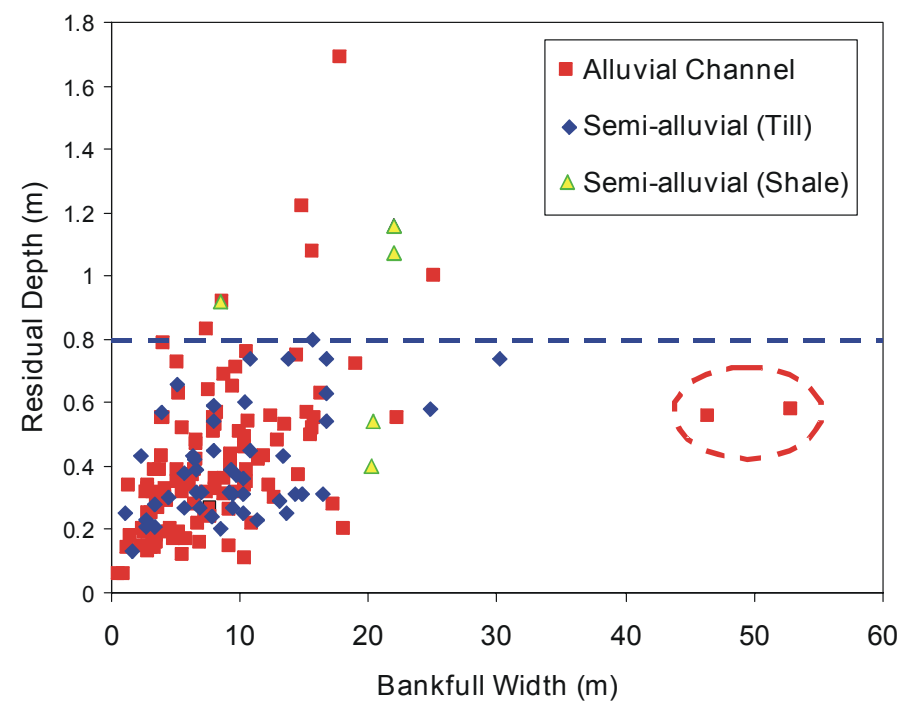

Figure 26.2 Residual depth as a function of bankfull width.

To characterize the flows in these channels bankfull shear stress was hindcast from the geomorphic data. Shear stress was selected over other hydraulic terms, such as stream power or average velocity, as it is consistent with the models presented later for mobilizing and flushing flows. Bankfull shear stress provides an estimate of the force acting on the bed during bankfull flow conditions. It is defined as:

$$
\tau_{B}=\rho g D_{B} s
$$

where:

$$
\begin{aligned}
& \rho=\text { density of water } \\
& g=\text { gravity }
\end{aligned}
$$




$$
\begin{aligned}
\mathrm{D}_{\mathrm{B}} & =\text { bankfull depth, and } \\
\mathrm{s} & =\text { bankfull slope. }
\end{aligned}
$$

A plot of residual depth as a function of bankfull shear stress (Figure 26.3) illustrates that although there is potentially a weak relation between residual depth and bankfull force, there is substantial variability. The outliers observed in Figure 26.2 fall within the greater population on Figure 26.3, indicating the limited pool development was a function of backwater effects.

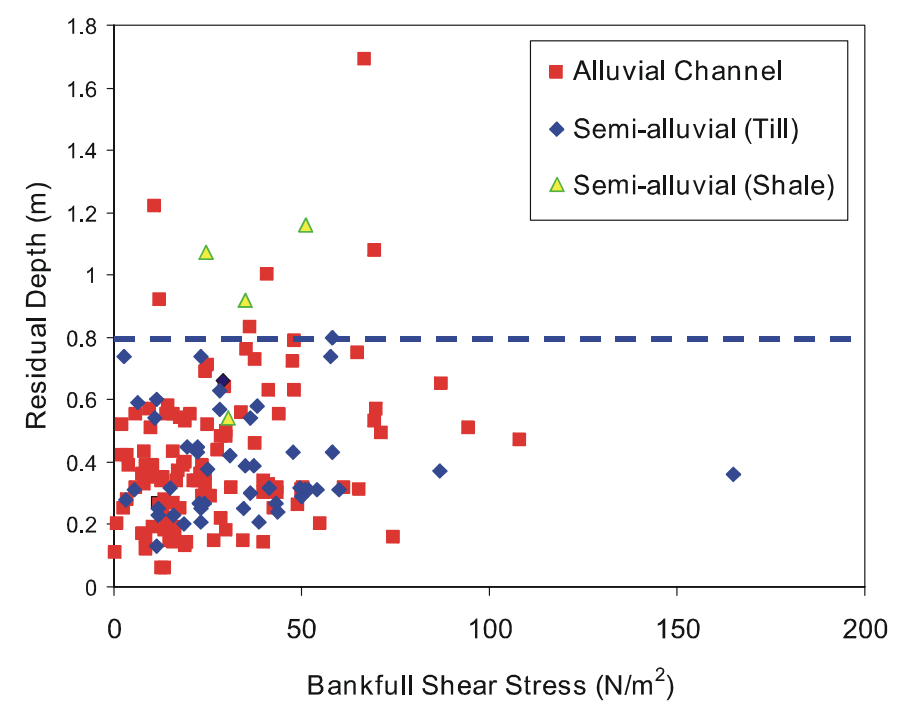

Figure 26.3 Residual pool depth as a function of bankfull shear stress.

Figure 26.4 provides an example of a till and shale dominated channel. Figure 26.4 (A) depicts a shale bed channel (Quenippenon Brook, Mississauga, Ontario) with a substantially deep pool. Figure 26.4 (B) depicts a till dominated section of Bowmanville Creek, Bowmanville, Ontario, that exhibits a lack of pool development as a result of clay till exposure on the channel bed. 

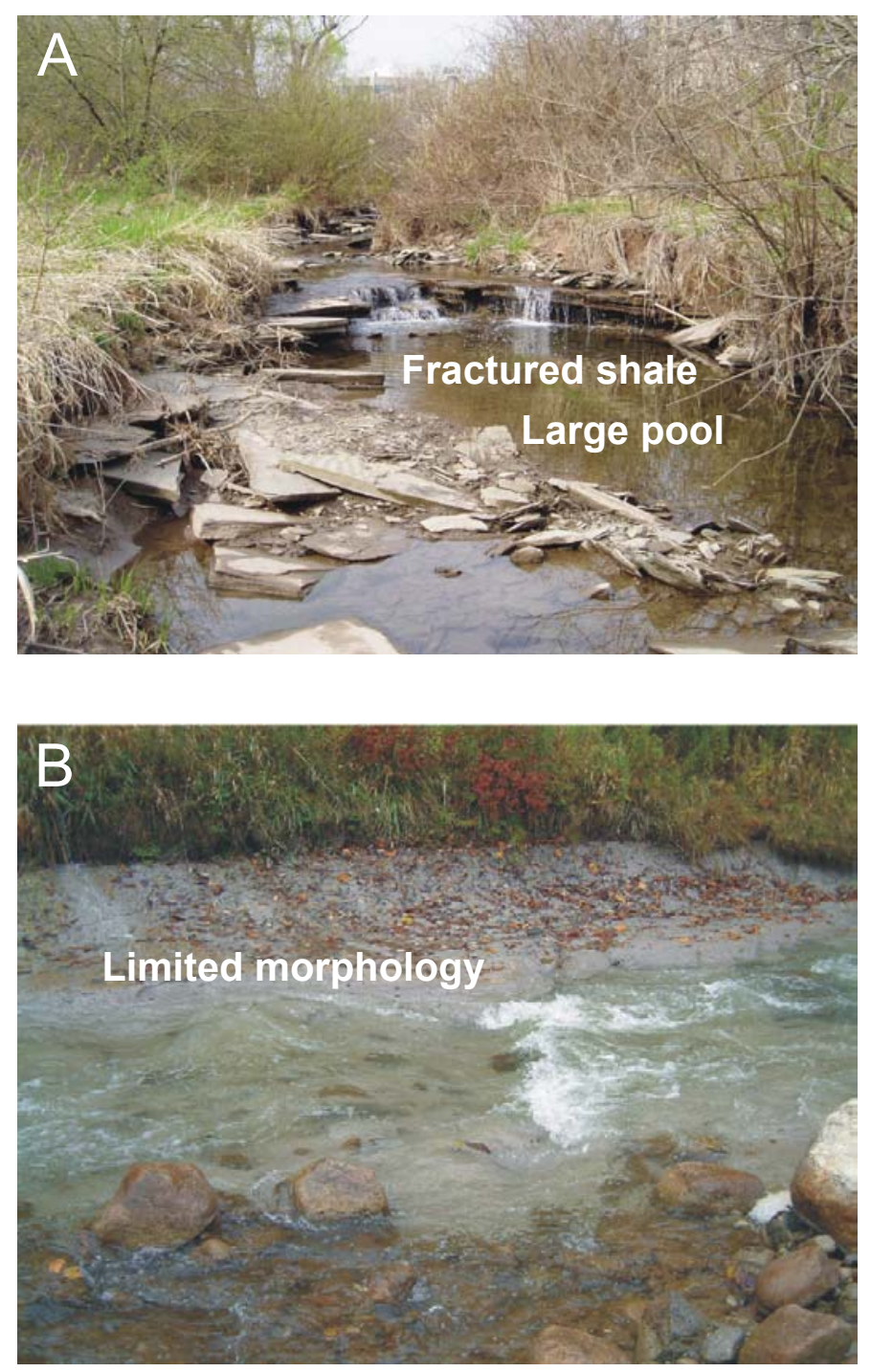

Figure 26.4 (A) The shale channel bed of Quenippenon Brook, Mississauga, promotes pool formation. (B) Bowmanville Creek, Bowmanville, exhibits a lack of pool development. 


\subsection{Bankfull, Flushing and Mobilizing Flows}

To examine potential mobilizing and flushing flows, two simple models are applied. Miller et. al.'s (1977) approach is used to define the shear stress associated with a mobilizing flow:

$$
\tau_{m}=0.045\left(\rho_{s}-\rho_{w}\right) g d_{50}
$$

where:

$$
\begin{aligned}
\rho_{\mathrm{s}} & =\text { the density of the sediment } \\
\rho_{\mathrm{w}} & =\text { the density of water, } \\
\mathrm{g} & =\text { gravity, and } \\
\mathrm{d}_{50} & =\text { the median grain size. }
\end{aligned}
$$

Assuming equal mobility, if the median grain size is mobilized all components of the bed are potentially mobilized. However, this is conceptual and in practice is not the case, particularly in channels with poorly sorted or bimodal sediment distributions. Still, it is useful as a first approximation. As this equation is for non-cohesive sediments, where the channel was dominated by fine cohesive sediment a critical shear stress of $4.5 \mathrm{~N} / \mathrm{m}^{2}$ was applied. This value is consistent with a weathered till (cohesive fines with limited compaction) (Chow, 1959; Fischenich, 2001). This is likely an adequate first approximation of the data available; as this is an assessment of the aggregate characteristics of these channels and there was limited information on the state of the cohesive sediments within the channels.

During flushing flows, it is expected that the fine sediments are mobilized, but not necessarily the coarser sediments. Therefore, a hiding function, which corrects for the protection of the fines by the larger particles was applied. In this case, Hey's (2001) hiding function is applied:

$$
\tau_{f}=0.0375\left(\frac{d_{i}}{d_{50}}\right)^{-0.872}\left(\rho_{s}-\rho_{w}\right) g d_{i}
$$

where $d_{i}$ is the grain size fraction of interest. By using a hiding function, it is possible to compute an apparent critical shear for the fine component within the channel, when the larger materials are not mobilized. Here an 
arbitrary division for fines was defined as sediment $<0.0126 \mathrm{~mm}$ (the division between medium sand and fine sand). This division was selected for this examination as accumulation of these fine materials can impact spawning beds.

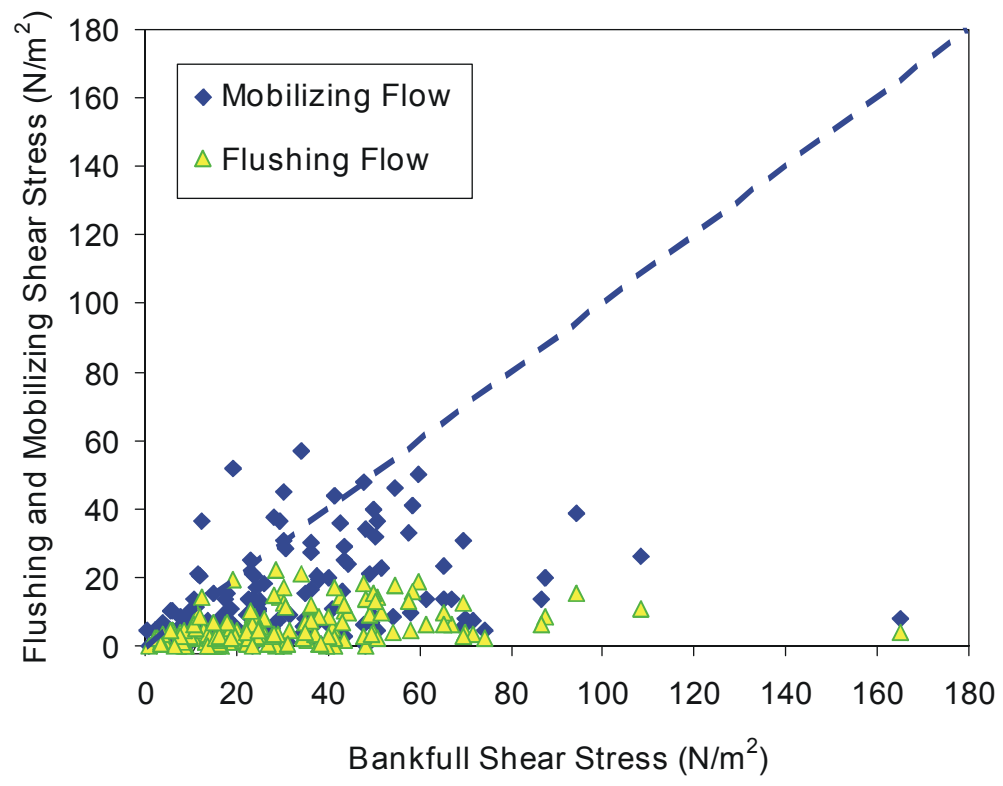

Figure 26.5 Flushing and mobilizing shear stress as a function of bankfull shear stress. The dashed line is the $1: 1 \mathrm{fit}$.

Figure 26.5 illustrates flushing and mobilizing shear stress as a function of bankfull shear stress. The dashed line is the 1:1 fit. The relation in Figure 26.5 suggests that mobilizing flows generally occur below bankfull conditions within the Greater Toronto Area. As the bankfull condition is associated with a return period of approximately $1.5-\mathrm{y}$, it indicates that flows that influence channel form and process can and do occur well below the 2-y return. Flushing flows occur well below bankfull and likely occur on a regular basis throughout the year. These flows are potentially important in maintaining riffles and spawning habitat. The scatter in the plot also illustrates that mobilizing and flushing flow conditions are unique to each channel as a result of the variability in local sediment conditions. 
It is possible that a portion of the apparent channel sensitivity illustrated by Figure 26.5 is a product of the model approach and assumptions. Other approaches to model entrainment, such as, stream power and or average velocity may have indicated less stream sensitivity. Given that the available hiding functions are based on shear stress assessing sensitivity of the relations to the modeling approach were limited.

\subsection{Conclusions}

TRCA data suggests that channels which are till-dominated produce smaller pools for the data set examined. These types of observations allow areas that are potentially sensitive to low flow conditions to be identified. It also suggests that it may be possible to identify these sites on the basis of controlling and influencing factors such as geology.

The modeling exercise with the TRCA data suggests that flushing and mobilizing flows occur well below the 2-y return for the data set examined. This illustrates the significance of lower magnitude, frequent flow events to the formation and maintenance of watercourse morphology. Therefore, it is important to develop methods to identify, manage and maintain these components of the flow regime.

Finally, the variability in residual depth and mobilizing and flushing flow conditions illustrates the importance of defining flow requirements on a siteby-site basis when developing stormwater management strategies.

Given the approximations and assumptions made in this chapter further evaluation are warranted, particularly assessing channel sensitivity through other modeling approaches.

\section{Acknowledgments}

Thanks to TRCA for allowing access to the TRCA Regional Monitoring Network data and for their continued support and interest in this work. We also thank Mr. Kevin Tabata at Geomorphic Solutions for his time and energy in developing the graphics for this chapter. Finally, we thank the reviewers for their constructive comments. 


\section{References}

Chow, V.T. 1959. Open-channel hydraulics. McGraw Hill. Boston MA.

Fischenich, C. 2001. Stability thresholds for stream restoration materials. USACE

Research and Development. Technical note SR-29. 10pp.

Hey, R. 1975. Design discharge for natural channels. In: Hey, R. D.; Davies, J. D., eds. Science technology and environmental management. Saxon House, Farnborough, 7388 .

Hey, R. 2001. Fluvial geomorphology for river engineers. Wildland Hydrology, Inc. Pagosa Springs.

Leopold, L.B., Wolman, M.G. and Miller, J.P. 1964. Fluvial Processes in geomorphology. Dover Publications, New York.

Lisle, T.E. 1987. Using "residual depths" to monitor pool depths independently of discharge. United States Department of Agriculture: Research Note PSW-394, 4pp.

Miller, M.C., McCave, I.N. and Komar, P.D. 1977. Threshold of sediment motion under unidirectional currents. Sedimentology 24, 507-527.

Wolman, M.G. 1954. A method of sampling coarse river bed material. Transactions of the American Geophysical Union, 35 (6): 951-956. 
